ASIAN BORDERLANDS

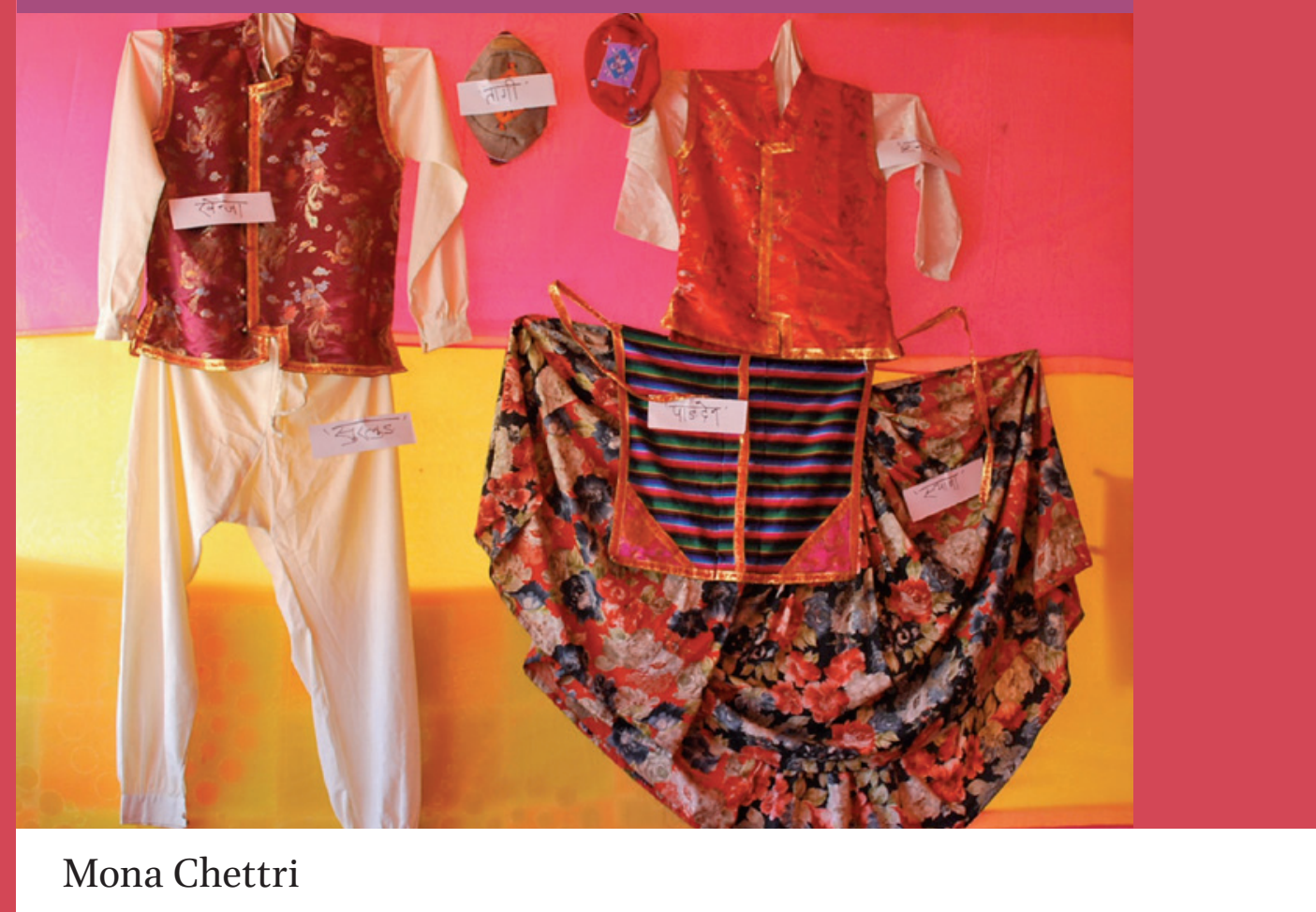

\title{
Ethnicity and Democracy in the Eastern Himalayan Borderland
}

Constructing Democracy 